\section{References}

BARRISON, I. G., VIOLA, L., MURRAY-LyON, I. M. (1980) Do housemen take an adequate drinking history? British Medical Journal. 281. 1040.

BERNARDT, M. W. \& MURRAY, R. M. (1986) Psychiatric disorder, drinking and alcoholism: what are the links? British Journal of Psychiatry. 148, 393-400.

DENT, T., SHEPHERD, R., LONDON, M., et al (1995) Education and audit can improve the identification of excessive drinkers among medical inpatients. Health Trends, 27. 92-97.

DePartment OF Health (1992) Health of the Nation: A Strategy for Health in Great Britain. London: HMSO.

ELus, M. \& DONALLY. P. (1991) Alcohol history taking. Psychiatric Bulletin, 15, 509.

FARID, B. T. (1991) CAGE (letter). Lancet, 338, 1089-1090.

FARRELl, M. P. \& DARUD, A. S. (1988) Do psychiatric registrars take a proper drinking history? British Medical Journal, 296, 395-396.

HOWARD, R. \& TURNER, G. (1989) Why don't we take adequate drinking histories from elderly admissions? British Journal of Addiction. 84, 1374-1375.

LOCKHART, S. P., CARTER, Y. H. \& STRAFFEN, A. M. (1986) Detecting alcohol consumption as a cause of emergency general medical admissions. Joumal of the Royal Society of Medicine, 79, 132-136.
MrTCHEL, C. (1989) Alcohol histories taken by psychiatric registrars: a comparative study in a non-teaching hospital. British Journal of Addiction, 84, 438-439.

NAIK, P. C. \& JONES, R. G. (1994) Alcohol historles taken from elderly people on admission. British Medical Journal, s08. 248.

SCHMIDT, L. (1995) The role of problem drinking in psychiatric admissions. Addiction, 80, 375-389.

WALLACE, P. (1986) Looking for patients at risk because of their drinking. Joumal of the Royal Society of Medicine. 79. 129.

*B. T. Farid, Consultant Psychiatrist in Substance Misuse, R. H. Bird, Senior Registrar in Substance Misuse, Community Alcohol Team. Drury House, 50 Leicester Road, Narborough, Leicester LE9 5DF; and B. Naik, Senior Registrar in Learning Disability, Glenfrith Hospital, Groby Road, Leicester LE3 9QF

*Correspondence

\title{
Attendance at child psychiatric clinics
}

\author{
A. Ubeysekara and N. Cox
}

\begin{abstract}
A study of 41 familles who falled to attend their first appointment at a child psychiatric clinic is described. The study was prospective over a period of one year and the families were interviewed personally; $14.9 \%$ failed their first appointment. Improvement of the child's symptoms during the waiting period, anxiety about seoing a psychiatrist/social worker, financial difficulties and the invitation to the family to attend were common reasons given for non-aftendance. Another important factor was that families were Ill-prepared by the referrers.
\end{abstract}

Out-patient clinic non-attendance occurs across all medical and psychiatric specialities leading to available resources not being used and patients not receiving the help they need in addition to negative effects on staff morale. In Toronto, $13.6 \%$ of those offered an appointment at the Child Psychiatric Clinic did not attend (Lefebvre et al, 1983). A three-month study at St George's Hospital Child Psychiatric Clinic in London showed that $15.9 \%$ failed their first appointment (Cottrell et al, 1988). At a child guidance clinic in a London borough, $26.8 \%$ of the referrals were never seen at the clinic, $15.9 \%$ failing to attend giving no warning of this (Richards, 1990). Thirty-six per cent of those offered a first appointment did not attend another National Health Service child and family psychiatric clinic (Jaffa \& Griffin, 1990) while a lower rate of $11.1 \%$ was found at a local child psychiatric clinic in Ireland (Belton \& O'Donovan, 1993).

Most studies were carried out retrospectively with a varying response rate from the families. A recurrent difficulty is the lack of information about the cases who do not attend (Cottrell et al, 1988). The present study, looking at the rate of non-attendance and associated factors, was 
done prospectively and non-attending families were interviewed personally to collect the information.

\section{The setting}

Mid Glamorgan Child and Family Service serves a population of 540000 through four consultant-led multi-disciplinary teams. The study involves referrals received by one consultant-led team serving two South Wales valleys with a population of about 150000 . The two valleys served by the clinical team have high socioeconomic problems, a significant proportion of families referred to the service having to depend on public transport to attend the clinic. The clinical team consists of a full-time consultant, two part-time doctors, two full-time social workers, and some input from a clinical psychologist on a flexible basis. All non-urgent referrals are generally seen between one to four weeks after the case allocation and a standard appointment letter is sent to the family inviting the family to attend.

\section{The study}

The study used all the referrals received by the clinical team over a period of 12 months in 1988. The families who were offered a clinic appointment but failed to attend their first appointment were included in the study. Those families who contacted the clinic to cancel the appointment. and the families who referred themselves, were excluded from the study. A questionnaire was developed, to be filled in by a therapist during a semi-structured interview with the parents. If the family kept their second appointment the questionnaire was filled in by their respective therapists, while all the other non-attending families were visited by one of the two social workers to complete the questionnaire.

\section{Findings}

In 1988 there were 341 new referrals, of whom $92(26.9 \%)$ failed to attend their first clinic appointment. Fifty-one (14.9\%) families failed, having not contacted the clinic and were included in the study. Nine families had to be excluded because they were self-referrals or had moved house, and one family refused to take part in the study. The remaining 41 'no show' families were interviewed to collect information required for the study.

\section{Child factors}

There were 29 male and 12 female children in the 'no show' group, with a mean age of eight years.
There were $12(29 \%)$ in the 1-5 age group, 18 $(44 \%)$ in the 6-11 group, and $11(27 \%)$ in the 12 17 group, which was not different from the total referred group. Ten out of 41 children were not willing to attend the clinic but only four families gave this as the main reason for non-attendance.

\section{Presenting symptoms}

Nearly half the non-attending children had one presenting symptom while $10 \%$ had three or more symptoms at the time of the referral. The duration of the presenting symptoms varied from a few weeks in two children, to over a year in 27 (66\%) children. The most common presenting symptoms were in the category of behaviour/ conduct group ( 31 children) while the other 10 children were referred for enuresis, encopresis, eating/sleeping difficulties, anxiety/depression or school attendance problems. In eight out of 41 children $(20 \%)$ the parents reported an improvement in the presenting symptoms during the waiting period before the first clinic appointment.

\section{Family factors}

There were 29 two-parent families, including 10 reconstituted families, while 12 children came from single parent families. Only 19 fathers and 10 mothers were employed at the time of the referral, and all the 26 families that we were able to categorise by social class belonged to social classes 3, 4 and 5. Sixteen families (39\%) described themselves as having financial difficulties and only $16(39 \%)$ had the use of a car. the others $(61 \%)$ having to travel by public transport. There were three or more children in $26(63 \%)$ families, while $10(25 \%)$ had two children and $5(12 \%)$ had only the referred child. Most parents (78\%) had faith in the helping agencies.

\section{Referral process}

The 'no show' families were referred by general practitioners, health visitors, paediatricians, social services departments and the education department, and there were no significant differences between the agencies. Two-thirds of the referrals were made at the instigation of the parents and $88 \%$ of the parents saw a need for the referral. The referrer had not explained the specific aim of the referral in $51 \%$ of cases. Similarly, nearly two-thirds of the referrers have not explained the help they may recelve or that there is a family approach.

\section{Clinic/therapist factors}

Eleven families had known about the Mid Glamorgan Child and Family Service before but 
only seven families have had any contact with the service. Two families $(5 \%)$ said that the distance to the clinic affected their non-attendance while seven (17\%) families felt that the invitation to the family to attend may have influenced their decision not to attend. Six families felt that they had to wait too long before the clinic appointment but only one family gave this as the sole reason for their non-attendance. The fact that they were going to be seen by a child psychiatrist or a social worker had a discouraging influence on seven and five families, respectively, seven of whom gave this as the main reason for not attending the clinic.

\section{Reasons given by the parents}

Eight families (20\%) did not attend as the presenting symptoms of the referred child improved during the waiting period, while another seven families (17\%) did not attend as they had to see a psychiatrist or a social worker. Child's refusal to attend caused four families (10\%) not to attend the clinic. Other reasons given by the parents were family illness, appointment letter not received, father's work shifts, lack of babysitters, lack of money for travelling, long waiting time and mother's agoraphobia.

\section{Comment}

The rates of $26.9 \%$ for total non-attendance and $14.9 \%$ for no shows at the first clinic appointment in two South Wales valleys appear to be similar to rates in child psychiatric clinics elsewhere. The non-attending children, or their symptoms, were not significantly different from the total referred group. In $20 \%$ of the nonattending children an improvement was reported during the waiting period but it is difficult to know whether it was a genuine resolution of the symptoms following a crisis or whether reorganisation of family and other factors managed to contain the symptoms to reappear later on. A shorter waiting period and/or some crisis intervention work may be more appropriate for this group of families. As the majority of nonattending families were non-car users, and some gave financial difficulties as the main reason for non-attending, transportation needs to be investigated, especially if the whole family is expected to attend. The families were ill-prepared by the referrers at the time of the referral. Hence, attempts should be made to educate the referrers through clinic brochures or face to face contact about the need to explain the nature of the service, including the family approach to allay parental anxieties about clinic attendance.

We seem to underestimate the parental anxiety about having to see a psychiatrist or a social worker with their child. A leaflet/booklet explaining the role and the functions of the clinic, sent along with the first appointment letter, may be helpful in reassuring at least some of the families with those anxieties.

\section{Acknowledgements}

Our grateful thanks to team members who helped us with parental interviews and to Mrs S. Roome.

\section{References}

BELTON, M. \& O'DONOVAN, A. (1993) Local child psychiatric service. Association for Child Psychology and Psychiatry Review and Newsletter, 15(3), 120-124.

CotTrell, D., Hill. P., WAlK. D., et al (1988) Factors influencing non-attendance at child psychiatry outpatient appointments. British Journal of Psychiatry. 152. 201-204.

JAFFA, T. \& GRIFFIN, S. (1990) Does a shorter wait for a first appointment improve the attendance rate in child psychiatry? Association for Child Psychology and Psychiatry Review and Newsletter, 12(2), 9-11.

Lefebvre, A., SOMmerauer, J., CohEn, N., et al (1983) Where did all the 'no-shows' go? Canadian Journal of Psychiatry. 28. 387-390.

RICHARDS. H. (1990) What do they do at the child guidance? Association for Child Psychology and Psychiatry Review and Newsletter, 12(3), 13-17.

*A. Ubeysekara, Consultant in Child and Adolescent Psychiatry, and N. Cox, Social Worker, Brynffynnon Child and Family Centre, Merthyr Road, Pontypridd, Mid Glamorgan CF37 $4 D D$

*Correspondence 